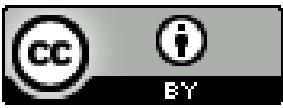

\title{
FRANTZ FANON E AS MÁSCARAS BRANCAS DA SAÚDE MENTAL: SUBSÍDIOS PARA UMA ABORDAGEM PSICOSSOCIAL
}

\author{
Deivison Mendes Faustino ${ }^{1}$ \\ Maria Clara dos Santos Oliveira ${ }^{2}$
}

Resumo: O presente artigo apresenta algumas contribuições do psiquiatra, filósofo e ativista anticolonial Frantz Fanon para o campo da saúde mental. O estudo pauta-se por uma análise exegética de seu primeiro livro Pele negra, máscaras brancas que buscou identificar algumas categorias-chave para a compreensão de sua propositura teórica onde se destaca a sociogenia e alienação colonial. A apresentação dos achados será discutida à luz da exposição da trajetória clínica do autor e do diálogo com a fortuna crítica especializada em seu pensamento. Argumentamos ao longo do artigo que essas categorias evidenciam a centralidade dos aspectos sociais sobre o sofrimento psíquico no qual se destaca o racismo. Ao final, valemo-nos desse referencial teórico para levantar alguns questionamentos a respeito da presença (ou ausência) do tema Racismo na agenda da saúde mental e na chamada Rede de Atenção Psicossocial (RAPS).

Palavras-chave: Frantz Fanon; sociogenia; saúde mental; racismo; sofrimento psíquico.

\section{FRANTZ FANON AND THE WHITE MASKS OF MENTAL HEALTH: SUBSIDIES FOR A PSYCHOSOCIAL APPROACH}

Abstract: This article presents some contributions by the psychiatrist, philosopher and anti-colonial activist Frantz Fanon to the field of mental health. The study is guided by an exegetical analysis of his first book Black skin, white masks that sought to identify some key categories for the understanding of his theoretical proposition where the sociogenesis and colonial alienation stand out. The presentation of the results will be

1 Doutor em Sociologia, Professor do Departamento de Saúde, Educação e Sociedade, da Universidade Federal de São Paulo e integrante do Instituto Amma Psique e Negritudes. ORCID: https://orcid.org/0000-0002-3454-7966 E-mail: sdeivison@ hotmail.com

2 Graduanda em Serviço Social, Universidade Federal de São Paulo e integrante do Núcleo Reflexos de Palmares. ORCID: https://orcid.org/0000-0001-7069-6769 E-mail: mm.claraoliveira@gmail.com

Revista da ABPN • v. 12, n. Ed. Especial - Caderno Temático: "III ANPSINEP Articulação Nacional de Psicólogas/os Negras/os e Pesquisadoras/es” • outubro de 2020, p. 6-26 
discussed based on the author's clinical trajectory and the dialogue with the critical fortune specialized in his thinking. We have argued throughout the article that these categories show the centrality of social aspects of psychological suffering, in which racism stands out. In the end, we used this theoretical framework to raise some questions about the presence (or absence) of the theme Racism in the mental health agenda and in the so-called Psychosocial Care Network (RAPS).

Keywords: Frantz Fanon; sociogeny; mental health; racism; psychic suffering

\section{FRANTZ FANON Y LAS MÁSCARAS BLANCAS DE LA SALUD MENTAL: SUBSIDIOS PARA UN ENFOQUE PSICOSOCIAL}

Resumen: Este artículo presenta algunas contribuciones del psiquiatra, filósofo y activista anticolonial Frantz Fanon para el campo de la salud mental. El estudio se guía por un análisis exegético de su primer libro Piel negra, máscaras blancas que buscaban identificar algunas categorías clave para la comprensión de su propuesta teórica donde se destaca la sociogénesis y la alienación colonial. La presentación de los resultados se discutirá en función de la trayectoria clínica del autor y el diálogo con la fortuna crítica especializada en su pensamiento. Hemos argumentado a lo largo del artículo que estas categorías muestran la centralidad de los aspectos sociales sobre el sufrimiento psicológico, en el que se destaca el racismo. Al final, utilizamos este marco teórico para plantear algunas preguntas sobre la presencia (o ausencia) del tema Racismo en la agenda de salud mental y en la llamada Red de Atención Psicosocial (RAPS).

Palabras-claves: Frantz Fanon; sociogenia; salud mental; racismo; sufrimiento psíquico

\section{FRANTZ FANON ET LES MASQUES BLANCS DE LA SANTÉ MENTALE: SUBVENTIONS POUR UNE APPROCHE PSYCHOSOCIALE}

Résumé: Cet article présente quelques contributions du psychiatre, philosophe et activiste anticolonialiste Frantz Fanon dans le domaine de la santé mentale. L'étude est guidée par une analyse exégétique de son premier livre Peau noire, masques blancs qui cherchait à identifier quelques catégories clés pour la compréhension de sa proposition théorique où se démarquent la sociogenèse et l'aliénation coloniale. La présentation des résultats sera discutée en fonction de la trajectoire clinique de l'auteur et du dialogue avec la fortune critique spécialisée dans sa pensée. Nous avons soutenu tout au long de l'article que ces catégories montrent la centralité des aspects sociaux de la souffrance psychologique, dans lesquels le racisme se démarque. En fin de compte, nous avons utilisé ce cadre théorique pour soulever quelques questions sur la présence (ou l'absence) du thème Racisme dans l'agenda de la santé mentale et dans le soi-disant Psychosocial Care Network (RAPS).

Mots clés: Frantz Fanon; sociogénie; santé mentale; racisme; souffrance psychique

\section{INTRODUÇÃO: RETIRANDO ALGUMAS MÁSCARAS}

Revista da ABPN • v. 12, n. Ed. Especial - Caderno Temático: "III ANPSINEP Articulação Nacional de Psicólogas/os Negras/os e Pesquisadoras/es” • outubro de 2020, p. 6-26 
Perguntais-me como me tornei louco. Aconteceu assim: Um dia, muito tempo antes de muitos deuses terem nascido, despertei de um sono profundo e notei que todas as minhas máscaras tinham sido roubadas - as sete máscaras que eu havia confeccionado e usado em sete vidas - e corri sem máscara pelas ruas cheias de gente gritando: "Ladrões, ladrões, malditos ladrões!". Homens e mulheres riram de mim e alguns correram para casa, com medo de mim. E quando cheguei à praça do mercado, um rapaz no cimo do telhado de uma casa gritou: "É um louco!". Olhei para cima, para vê-lo. O sol beijou pela primeira vez a minha face nua. Pela primeira vez, o sol beijava a minha face nua, e a minha alma inflamou-se de amor pelo sol, e não desejei mais as minhas máscaras. E, como num transe, gritei: "Benditos, benditos os ladrões que roubaram as minhas máscaras!". Assim tornei-me louco (GIBRAN KHALIL GIBRAN).

O presente estudo tomou o livro Pele negra, máscaras brancas (2008) como fonte privilegiada de reflexões do psiquiatra, filósofo e militante anticolonial, Frantz Fanon, sobre o racismo, a subjetividade, o sofrimento psíquico e, sobretudo, o trato institucional desses elementos no âmbito da Saúde mental.

Frantz Omar Fanon nasceu no dia 20 de julho de 1925, na ilha caribenha de Martinica, atual departamento ultramarino da França, onde a maior parte da população era composta por pessoas negras que se viam como francesas. Em 1944, com a anexação de parte do território francês à Alemanha nazista, Fanon alistou-se em uma frente política e guerrilheira, La Résistance, com o objetivo de combater militarmente as forças hitleristas. Enquanto estava no front de guerra, arriscando-se pela pátria que considerava sua, descobriu que, aos olhos dos franceses em geral, um preto era apenas um preto, jamais um francês (FAUSTINO, 2018a). Esse incidente ficou conhecido como uma das grandes rupturas narcísicas vivida por Fanon.

Algum tempo depois, na França continental, ao estudar psiquiatria forense na Faculdade de Psiquiatria de Lyon, Fanon participou do movimento estudantil, escreveu peças teatrais e acabou se tornando pai sem ter planejado. Ao final de sua graduação, decidiu apresentar um Trabalho de Conclusão de Curso com algumas reflexões que vinha fazendo sobre o racismo e suas consequências para a subjetividade. Nesse trabalho, abordou questões como a linguagem; relacionamentos interraciais; imigração e xenofobia; movimentos emancipatórios; cultura e política; bem como as encruzilhadas ontológicas e gnosiológicas entre a singularidade e a universalidade humanas, em um

Revista da ABPN • v. 12, n. Ed. Especial - Caderno Temático: “III ANPSINEP Articulação Nacional de Psicólogas/os Negras/os e Pesquisadoras/es” • outubro de 2020, p. 6-26 
contexto colonial. O texto - que mobilizava em sua fundamentação os repertórios técnicos e teóricos da psicanálise, do marxismo, existencialismo, movimento de negritude e, sobretudo, da filosofia hegeliana - foi batizado como Essai sur la désalienation Du Noir [Ensaio sobre a desalienação do negro].

No entanto, o manuscrito foi rejeitado pelo orientador por ser considerado inapropriado para um curso de psiquiatria. Ao que parece, não havia espaço - mesmo na faculdade em que um dos docentes era Maurice Merleau-Ponty (1908-1961) - para um ensaio teórico sobre a subjetividade negra. Frustrado, o jovem estudante arquiva o seu manuscrito e se empenha na redação acelerada de um segundo estudo, dessa vez, mais atento aos limites impostos pelo ambiente teórico em que se encontrava.

O segundo trabalho, aceito pelo orientador e aprovado com louvor pela banca, foi intitulado Troubles mentaux et syndromes psychiatriques dans l'HérédoDégénération-Spino-Cérébelleuse. Un cas de maladie de Friedreich avec délire de possession [Transtornos mentais e síndromes psiquiátricas em Hérédo-DegeneraçãoSpino-cerebelar: um caso de doença de Friedreich com delírios de possessão]. Ainda assim, com esse trabalho, que objetivava responder aos anseios positivistas do curso, o jovem estudante não deixou de apontar a necessidade de observar os pacientes em seus contextos socioculturais de existência (FAUSTINO, 2018a).

Após a conclusão do curso, Fanon apresentou seu manuscrito rejeitado à Éditions Du Seuil, dirigida pelo intelectual e ativista de esquerda francês, Francis Jeanson. Depois de aceito o Essai sur la désalienation Du Noir teve seu título alterado para o Pele negra, máscaras brancas. É a esse texto que o presente estudo se refere. No entanto, antes de iniciar a análise, parece útil apresentar de maneira panorâmica os passos seguintes dados por Fanon, uma vez que evidenciam a importância do campo da Saúde mental em sua trajetória.

Após a conclusão do curso de psiquiatria, o jovem médico decide fazer residência médica com o renomado médico catalão François Tosquelles, em Saint Alban, onde trabalhou, pesquisou e escreveu alguns trabalhos de investigação científica durante dois anos (FAUSTINO, 2018a). Da perspectiva do jovem psiquiatra martinicano, Tosquelles apontava possibilidades concretas de superar alguns dos problemas identificados em seu livro Pele negra, máscaras brancas. 
$\mathrm{Na}$ formulação tosquelliana: se as alienações psíquicas tinham origem em uma sociedade que milita contra a humanidade de determinadas pessoas, a superação do sofrimento psíquico passaria, em primeiro lugar, pela reorganização das instituições de cuidado em saúde mental, de forma a considerar o impacto das desigualdades sociais sobre o sofrimento psíquico (FAUSTINO, 2020). Posteriormente, conclui que o sucesso da reforma psiquiátrica proposta passaria, necessariamente, por uma luta revolucionária que desmantelasse o colonialismo - em sua sistemática negação de humanidade e promoção de sofrimento psíquico - e instaurasse uma nova sociabilidade (KHALFA, 2020).

Em 1953, Fanon interrompeu seus estudos junto ao mestre espanhol para se preparar para os exames do Le Médicat des Hôpitaux Psychiatriques, concurso que permitiria ao aprovado escolher um posto de chef de service em algumas das mais importantes instituições psiquiátricas da França (FAUSTINO, 2018a). Após a aprovação com distinção no concurso, chega a atuar como diretor de um hospital psiquiátrico em Pontorson, por alguns meses, e depois, se transfere para a Blida, Argélia, território africano sob ocupação colonial francesa desde o século XIX. Essa nova fase foi fundamental para a sua compreensão a respeito dos impactos do colonialismo na estrutura psíquica humana, ao se deparar com diversos pacientes franceses e argelinos agonizando por transtornos mentais provocados pela violência anticolonial (OTO, 2003).

A presença centenária do colonialismo se fazia sentir na área da saúde. De acordo com Fanon, ainda naquela altura, ensinava-se, nas escolas de psiquiatria que o cérebro normal de um negro, ou um árabe, equivaleria, em habilidades e raciocínio lógico, ao cérebro de um branco lobotomizado. Assim, diante de tal orientação, as pessoas vítimas de doenças psíquicas eram separadas não conforme a gravidade daquilo que se entendia como doença, mas sim, segundo os seus marcadores sociais de diferença: árabes de um lado e franceses de outro.

Frantz Fanon, inspirado nos ensinamentos de Toscquelles e mediado por um inegociável senso ético, introduziu reformas estruturais nesse hospital, como o fim da distinção entre o europeu e o indígena - e a consequente organização das alas psiquiátricas a partir da gravidade do sofrimento, o uso da camisa de força apenas para quem e nos momentos em que representasse risco a si próprio, bem como a utilização 
de debates, oficinas, organização de jogos de futebol, feiras de artesanato e outras atividades com as comunidades vizinhas (FAUSTINO, 2018a). Ainda assim, seguia apostando que a resposta para o sofrimento psíquico encontrava-se não apenas na reforma da instituição psiquiátrica, mas, principalmente, na transformação radical da sociedade que o engendra (FAUSTINO, 2020, KHALFA, 2020).

$\mathrm{Na}$ época em que implementava essas mudanças no hospital, eclodiu o irreversível movimento de libertação nacional que resultou em uma repressão sanguinária protagonizada pelo exército francês. A partir daí os movimentos nacionalistas e independentistas ganharam força e a temática da "libertação" se apresentou como incontornável a qualquer intelectual que estivesse na França ou em suas colônias. Fanon não hesitou em se posicionar e tomar partido pela independência da Argélia. Com o acirramento das lutas de libertação, deparou-se com uma crescente tensão social que o colocou em uma situação bastante desconfortável: de dia, como diretor de um hospital público, recebia e atendia torturadores franceses que ficavam atordoados com o sofrimento que infringiam aos nativos rebeldes e, de noite, clandestinamente, atendia os guerrilheiros, vítimas da tortura. Foi nesse contexto que Fanon (1980, p. 59) escreveu: "Há longos meses que a minha consciência é palco de debates imperdoáveis. E a conclusão que chego é a vontade de não desesperar do homem, isto é, de mim próprio”. Vigiado pela polícia francesa, sua situação fica insustentável, especialmente porque ele começava a treinar clandestinamente os militantes em técnicas de primeiros socorros e a desviar medicamentos para os postos rebeldes - Ele, que a essa altura já era um militante clandestino da Frente de Libertação Nacional - desligou-se do hospital e aderiu oficialmente à revolução. Foi nesse momento que escreveu uma carta pública que explicita as suas origens tosquellianas:

A loucura é um dos meios que o homem tem de perder a sua liberdade. E posso dizer que, colocado nesta intersecção, medi com horror a amplitude da alienação dos habitantes deste país. Se a psiquiatria é a técnica médica que se propõe permitir ao homem deixar de ser estranho ao que o rodeia, devo afirmar que o Árabe, alienado permanentemente no seu país, vive num estado de despersonalização absoluta (FANON, 1980, p. 58).

O resultado da carta foi a expulsão de Fanon do território argelino (MACEY, 2000). Assim se refugiou na Tunísia, onde seguiu atuando na clínica psíquica, fiel à sua 
proposição teórica de engajamento na luta contra a opressão e a exploração como principal profilaxia. Com a abertura a novas ideias e, ao mesmo tempo, a liberdade para seguir como intelectual orgânico da Frente de Libertação Nacional da Argélia, a Tunísia, recém-independente, representava para ele a possibilidade de pôr em prática a sua tese de que as doenças mentais se curariam com a transformação radical da sociedade. Fanon morreu de leucemia em 1961, quando tinha 36 anos. No ano seguinte a Argélia conquista a sua independência.

Com essa exposição biográfica tem-se o objetivo de enfatizar a trajetória clínica de Fanon e a importância da Saúde mental para o conjunto de suas reflexões sociológicas, políticas e filosóficas, elementos esses pouco explorados na literatura especializada em seu pensamento. Foi neste período de intensa atividade clínica que ele escreveu os seus principais ensaios sociológicos onde, não apenas abordava o sofrimento psíquico provocado pelo racismo colonial, como defendia o engajamento político na luta revolucionária como única possibilidade de "desintoxicação" (FAUSTINO, 2015). No entanto, só recentemente, passa a ser referido como um autor relevante para o campo da Saúde mental, embora ainda continue "pouco conhecido pelo público universitário do campo médico e da saúde" (OLIVEIRA, 2018, p. 52).

Esse desconhecimento é, no mínimo, curioso em um país como o Brasil, em que o campo da saúde mental fora tão marcado pelo movimento de luta antimanicomial - do qual Fanon foi parte ativa. A sua contribuição para esse movimento é comentada, inclusive, pelo psiquiatra italiano Ernesto Venturini (2012), um dos colaboradores do famoso psiquiatra antimanicomialista Franco Basaglia. Basaglia foi o principal formulador e implementador da Psiquiatria democrática na Itália, entre as décadas de 1960 e 1970. O movimento italiano foi a grande inspiração para a reforma psiquiátrica brasileira, bem como os decorrentes tratados e epistemes criados em torno da saúde mental. De todos os pensadores que influenciaram a proposta basagliana - entre os quais se destacam nomes como M. Foucault; A. Artaud; E. Goffman; R. Laing; W. Benjamin; T. Kuhn; A. Gramsci; e Ivan Illich - nenhum foi tão decisivo quanto Fanon. Como argumenta Venturini ao retomar a experiência de Gorizia, tão importante ao movimento de reforma: 
Existe um momento que simbolicamente aproxima a experiência de Fanon com a experiência de Gorizia. Em 1956 Fanon apresenta a sua demissão do hospital psiquiátrico de Blida e escreve uma carta famosa sobre o perigo da desmistificação terapêutica e a necessidade da luta revolucionária. Em 1972, nós, os psiquiatras da equipe em Gorizia, resolvemos dar alta, no mesmo dia, a todos os internados do hospital, depois apresentamos nossas demissões e nos dirigimos, com uma carta, aos usuários para explicar as motivações do gesto. (VENTURINI, 2012, p. 54).

De porte dessas informações, mas também amparada pelo relativo crescimento de investigações psicológicas que equacionam as relações entre racismo e saúde mental (MARTINS; SANTOS, 2013) e, sobretudo, pela possibilidade de uma clínica implicada ou interventiva diante do racismo (ROSA; BRAGA, 2017; DAVID, 2018), Rachel Gouveia Passos (2018) se pergunta: Como pode o movimento antimanicomial no Brasil - um país que passou a maior parte da sua história sob a escravidão racial e que, após seu fim, não criou nenhum dispositivo de reparação histórica, cultural e econômica, mas, sobretudo, de reelaboração psíquica dessa experiência - ter sido tão radical e ousado em suas propostas de inspiração basagliana, sem, contudo debater o racismo como elemento central de sofrimento psíquico e manicomialização de grupos tidos como indesejáveis? Por que falamos de Basaglia enquanto silenciamos a respeito de uma de suas principais referências clínicas, políticas e teóricas?

$\mathrm{Na}$ esteira desse questionamento, mas direcionando-o à experiência de trabalho com o tema no Instituto Amma Psique e Negritude e no Núcleo de Pesquisas Reflexos de Palmares, oferecemos, neste artigo, alguns subsídios iniciais à seguinte pergunta: Quais são as principais contribuições de Frantz Fanon para a área da saúde mental e às perspectivas defendidas na luta antimanicoMial? O objeto aqui delimitado nos coloca diante da possibilidade de um diálogo interdisciplinar entre vertentes e abordagens diversas da sociologia, filosofia, e psicologia, de forma a analisar as relações entre racismo, sofrimento psíquico e a possibilidade de uma clínica política que articule o sujeito ao seu enlaçamento social (ROSA, 2013).

$\mathrm{Na}$ coleta de dados aqui empreendida, buscou-se identificar categorias-chave ao longo do livro Pele negra, máscaras brancas, de Frantz Fanon (2008). Para este artigo, apresentaremos duas categorias encontradas, a saber: sociogenia e a alienação colonial, para, em seguida, apresentar algumas provocações mais gerais para o campo da Saúde Mental. 


\section{O.}

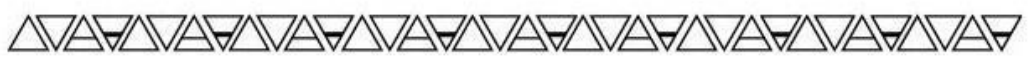

\section{A SOCIOGENIA DO SOFRIMENTO PSICOSSOCIAL}

A análise fanoniana do colonialismo relaciona tanto o "impacto do mundo social sobre a emergência dos sentidos e identidades humanas" quanto "as situações individuais que se relacionam com o desenvolvimento e a preservação política e social das instituições" (GORDON, 2015, p. 2). No mesmo período histórico que se apontava, ainda que contra-hegemonicamente, no campo da organização das práticas de saúde, para a superação dos limites disciplinares entre a intervenção social em saúde pública e a clínica (AYRES, PAIVA E FRANÇA 2010/2012), ${ }^{3}$ Fanon, a seu modo e em diálogo crítico com a psicanálise freudiana, afirmava:

Reagindo contra a tendência constitucionalista em psicologia do fim do século XIX, Freud, através da psicanálise, exigiu que fosse levado em consideração o fator individual. Ele substituiu a tese filogenética pela perspectiva ontogenética. Veremos que a alienação do negro não é só uma questão individual. Ao lado da filogenia e da ontogenia, há a sociogenia. De certo modo, para responder à exigência de Leconte e Damey, digamos que o que pretendemos aqui é estabelecer um sócio-diagnóstico (FANON, 2008, p. 28, grifos nossos).

A psicologia filogenética, ou constitucional, relaciona o comportamento humano à morfologia e à fisiologia, criando uma correlação entre o perfil corporal e as características psicológicas dos sujeitos. Fanon, psiquiatra preocupado com as dimensões sociais do sofrimento psíquico, comemora a ruptura representada pela psicanálise freudiana, mas reforça as sugestões do próprio Freud em relação à necessidade de ir além da dimensão psicoafetiva do desejo, compreendendo-a em seus

\footnotetext{
${ }^{3}$ Referimo-nos aqui ao avanço representado pela introdução de variáveis sociais na psicologia da saúde, iniciado na década de 1950 com o modelo da "História Natural das Doenças" (HDN); a "Nova Promoção da Saúde" (NPS), na década de 1970 e o quadro da vulnerabilidade e dos direitos humanos (V\&DH), no contexto de respostas ao HIV/Aids. A reformulação desses marcos diante de questões concretas vividas por sujeitos em situação de discriminação resultou na oferta, por parte da vertente brasileira da V\&DH da perspectiva psicossocial. Aposta-se que essa guinada permite ampliar os meios de instrumentalizar o acolhimento e o cuidado para além da chamada saúde mental em um diálogo mais amplo com as ciências sociais e, sobretudo, com as respostas práticas que setores marginalizados desenvolvem (PAIVA, 2013).
} 
contextos histórico e social concretos. Por essa razão, é enfático ao dizer: "O prognóstico está nas mãos daqueles que quiserem sacudir as raízes contaminadas do edifício, [pois] a Sociedade, ao contrário dos processos bioquímicos, não escapa da influência humana. É pelo homem que a sociedade chega ao ser" (FANON, 2008, p. 28).

Isso significa que, para ele, os processos pelos quais o colonialismo se constitui - bem como as suas implicações traumáticas para a subjetividade do colonizado - só se tornam inteligíveis quando tomados em suas determinações historicamente concretas: A modernidade capitalista e a sua necessidade de converter o que é genuinamente humano em objeto de sua acumulação. Por isso, insiste:

A análise que empreendemos é psicológica. No entanto, permanece evidente que a verdadeira desalienação do negro implica uma súbita tomada de consciência das realidades econômicas e sociais. Só há complexo de inferioridade após um duplo processo: - inicialmente econômico; - em seguida, pela interiorização, ou melhor pela epidermização dessa inferioridade (FANON, 2008, p. 28).

Por outro lado, essa "tomada de consciência" deveria ser pautada por uma análise que ultrapassasse a dimensão meramente econômica da dominação. O próprio marxismo francês do século XX, com o qual Fanon dialoga criticamente ao longo da sua produção, precisaria, segundo argumenta, ser "estendido" para dar conta desse mundo (colonial) onde até a dialética opera com restrições:

Quando se percebe na sua imediatez o contexto colonial, é patente de que aquilo que fragmenta o mundo é primeiro o fato de pertencer ou não a tal espécie, a tal raça. Nas colônias, a infraestrutura econômica é também uma superestrutura. A causa é consequência: alguém é rico porque é branco, alguém é branco porque é rico. É por isso que as análises marxistas devem ser ligeiramente estendidas, a cada vez que se aborda o problema colonial (FANON, 2010, p.56).

Assim, em um primeiro nível da análise, Fanon ressalta quanto o racismo e a racialização - implícita à situação colonial - são parte de um processo maior de dominação: a violenta e desigual expansão das relações capitalistas de produção para o mundo não europeu. No entanto, esses processos de diferenciação racializada não se limitaram à gênese do capitalismo e nem ao período assumidamente colonial do restante do mundo forçadamente convertido à sua lógica produtiva. Ao contrário, seguem nos 
colocando o desafio de equacionar até que ponto a crueldade das instituições modernas (FREUD, 1972) guarda de colonial (FAUSTINO, 2018b).

Embora encontre, nessa fase de acumulação capitalista a potencialização do rompimento de seus laços sociais pertinentes a uma possível gratificação narcísica, é mister reconhecer que a desorganização subjetiva decorrente da emergência daquilo que está fora do sentido e da significação (ROSA, 2004) foi a tônica sistêmica da inserção produtiva (e, portanto, social) desses sujeitos que chegaram ao "novo mundo" na condição de escravos-objetos e seguiram estruturalmente objetificados, mesmo após a abolição da escravidão (FAUSTINO, 2010; 2013a; 2013b; MOURA, 1994b; 1994b).

Essa proposição permite pensar, portanto, que o racismo - como ideologia (MOURA, 1994a) com efeitos concretos ao metabolismo social (MÉSZAROS, 2006) representa uma das modalidades de violência sistêmica geradoras do sofrimento psicossocial e, em alguns casos, inclusive de adoecimento (CRP, 2007).

O outro ponto que vale destacar é a ideia fanoniana de alienação colonial. Esta categoria, abundantemente abordada no já referido documento é um fenômeno socialmente construído que marca a configuração da sociedade moderna ao eleger o ocidente - ou os europeus - como expressões universais do gênero humano. ${ }^{4} \mathrm{Nessa}$ fantasia narcisista, o branco figura sempre como símbolo ontológico de "bom, belo e verdadeiro" e, por esse motivo encarna, em seu "raquítico corpo pensante", 5 a representação da razão, do progresso, da civilização, modernidade e, sobretudo, daquilo que nos distinguiria do reino animal: a ideia de sermos sujeitos de nossos próprios pressupostos. O branco é alçado à universalidade e, diante dela, nem precisa mais ser

${ }^{4}$ Ver a esse respeito o capítulo I intitulado “O negro e a linguagem” (FANON, 2008).

${ }^{5}$ Fanon (2008, p. 143) nos provoca ao afirmar que "qualquer aquisição intelectual exige uma perda do potencial sexual. O branco civilizado conserva a nostalgia irracional de épocas extraordinárias de permissividade sexual, cenas orgiásticas, estupros não sancionados, incestos não reprimidos. Essas fantasias, em certo sentido, respondem ao conceito de instinto vital de Freud. Projetando suas intenções no preto, o branco se comporta 'como se' o preto as tivesse realmente. Quando se trata do judeu, o problema é nítido: desconfia-se dele, pois ele quer possuir as riquezas ou se instalar nos postos de comando. O preto é fixado no genital, ou pelo menos aí foi fixado. Dois domínios: o intelectual e o sexual. O pensador de Rodin em ereção, eis uma imagem que chocaria. Não se pode, decentemente, 'bancar o durão' toda hora" (grifos do autor). 
especificado. Ao falar do humano, é ao branco que nos referimos e ele, portanto, nem precisa pensar que é branco, entende-se simplesmente como humano (FAUSTINO, 2017).

Aos negros e às negras, frequentemente invisíveis quando se pensa o humano em suas dimensões genéricas e complexas, resta a posição de depositário das qualidades que o ocidente deixa de reconhecer em si. Assim, ora figuram como o oposto de bom, belo e verdadeiro, ora como simples expressão de uma natureza "infantil" que ainda não teria ingressado na marcha histórica do espírito absoluto em direção à universalidade e liberdade (FAUSTINO, 2013a). O que está em jogo aqui, para Fanon, é a defesa de que o racismo não se limita às expressões inferiorizadoras e animalizadoras das populações não brancas, mas, sobretudo, expressa-se pela própria representação de uma humanidade genérica que abrange sempre a Europa (burguesa), o ocidente, o homem branco e suas expressões universais. Como afirma:

Na Europa, o Mal é representado pelo negro. [...] O carrasco é o homem negro, Satã é negro, fala-se de trevas, quando se é sujo, se é negro - tanto faz que isso se refira à sujeira física ou à sujeira moral. Ficaríamos surpresos se nos déssemos ao trabalho de reunir um grande número de expressões que fazem do negro o pecado. Na Europa, o preto, seja concreta, seja simbolicamente, representa o lado ruim da personalidade. [...] O negro, o obscuro, a sombra, as trevas, a noite, os labirintos da terra, as profundezas abissais, enegrecer a reputação de alguém; e, do outro lado: o olhar claro da inocência, a pomba branca da paz, a luz feérica, paradisíaca. Uma magnífica criança loura, quanta paz nessa expressão, quanta alegria e, principalmente, quanta esperança! Nada de comparável com uma magnífica criança negra, algo absolutamente insólito. Não vou voltar às histórias dos anjos negros. Na Europa, isto é, em todos os países civilizados e civilizadores, o negro simboliza o pecado. $\mathrm{O}$ arquétipo dos valores inferiores é representado pelo negro (FANON, 2008, p. 160, grifos do autor).

O problema apontado, no entanto, é ainda mais complexo, pois essas imagens, criadas (pelo branco e em benefício de sua supremacia) no contexto colonial, não se limitam à sua visão turva de mundo, mas influenciam, quase que como "catarse coletiva" (FANON, 2008:130/162), também a visão de negros e negras sobre si e exercem uma influência devastadora para a subjetividade, ao passo que produzem sentimento de incontornável inadequação.

No entanto, alerta o autor, a ideia de catarse é analiticamente útil, apenas se for pensada em sua dimensão cultural, ou adquirida, e não inata, ou transcendental. A essa 
altura, Fanon é bastante crítico com certa psicanálise que confunde, segundo argumenta, "instinto e hábito" ao justificar arquétipos racializados de forma naturalizada ou mística, ignorando com isso a gênese colonial - leia-se, histórica - de sua configuração. ${ }^{6} \mathrm{O}$ ponto é que o negro, diante de uma sociedade que apresenta sistematicamente o branco como única forma de ser humano, interioriza as imagens reificadas que criaram para si e, ao olhar no espelho, partilha com o branco de sua repulsa diante do que vê:

O inconsciente coletivo não depende de uma herança cerebral: é a consequência do que eu chamaria de imposição cultural irrefletida. Nada de surpreendente, pois que o antilhano, submetido ao método do sonho em vigília, reviva as mesmas fantasias de um europeu. É que o antilhano tem o mesmo inconsciente coletivo do europeu. Se o que acabou de ser dito faz sentido, estamos em condições de anunciar a conclusão seguinte: é normal que o antilhano seja negrófobo. Pelo inconsciente coletivo o antilhano adotou como seus todos os arquétipos do europeu. A anima do negro antilhano é quase sempre uma branca. Do mesmo modo, o animus dos antilhanos é sempre um branco (FANON, 2008, p. 162, grifos do autor).

Isso significa, em primeiro lugar, que o negro, ao buscar a sua humanidade no outro, encontra apenas imagens animalizadas e objetificantes acerca de si. Não se trata de afirmar que a imagem devolvida a mim pelo outro é sempre uma distorção recíproca, mas sim, para o negro, que esse reflexo turvo devolvido pelo olhar do outro é, em geral, apenas a reprodução de imagens fetichizadas criadas no contexto colonial. Em segundo lugar, esse ser que ainda é sujeito - embora nunca seja reconhecido como tal -, impedido de ter a sua humanidade confirmada pelo outro e imbuído apenas deste olhar reificador, aprende desde muito cedo a olhar-se também como um ente inexistente ou inadequado,

\footnotetext{
${ }^{6}$ A crítica fanoniana trata aqui, nomeadamente, do insuspeito Jung, pois, como afirma o jovem martinicano "A civilização europeia, no seio do que Jung chama de inconsciente coletivo, caracteriza-se pela presença de um arquétipo: expressão dos maus instintos, do lado obscuro inerente a qualquer ego, do selvagem não civilizado, do preto adormecido em cada branco. E Jung afirma ter constatado nos povos não civilizados a mesma estrutura psíquica que reproduz seu diagrama. Pessoalmente, penso que Jung se enganou. Aliás, todos os povos que ele conheceu - índios pueblos do Arizona ou negros do Quênia, na África Oriental britânica, tiveram contactos mais ou menos traumatizantes com os brancos. Dissemos anteriormente que, nas suas salavinizações, o jovem antilhano nunca é negro, e tentamos mostrar a que corresponde este fenômeno. Jung situa o inconsciente coletivo na substância cerebral herdada" (FANON, 2008, p. 159).
} 
interiorizando a imagem que o seu algoz lhe impôs. Diante do branco, o negro percebese inferior:

A estrutura neurótica de um indivíduo será justamente a elaboração, a formação, a eclosão no ego de nódulos conflituais provenientes em parte do meio ambiente, em parte da maneira toda pessoal com que este indivíduo reage a essas influências. [...] De modo algum minha cor deve ser percebida como uma tara. A partir do momento em que o preto aceita a clivagem imposta pelo europeu, não tem mais sossego, e, "desde então, não é compreensível que tente elevar-se até o branco? Elevar-se na gama de cores às quais o branco confere uma espécie de hierarquia?" (FANON, 2008, p. 82).

Em consequência, o conhecimento de si do negro - que em Fanon tem no corpo o seu ponto de partida - não é a emancipadora identidade hegeliana rumo à certeza e afirmação de quem é, mas, diferente disso, "atividade de negação". Um "conhecimento em terceira pessoa", completamente atravessado por "uma atmosfera densa de incertezas", que impõe dificuldades para a elaboração de seu esquema corporal:

Sei que, se quiser fumar, terei de estender o braço direito e pegar o pacote de cigarros que se encontra na outra extremidade da mesa. Os fósforos estão na gaveta da esquerda, é preciso recuar um pouco. Faço todos esses gestos não por hábito, mas por um conhecimento implícito. Lenta construção de meu eu enquanto corpo, no seio de um mundo espacial e temporal, tal parece ser o esquema. Este não se impõe a mim, é mais uma estruturação definitiva do eu e do mundo - definitiva, pois entre meu corpo e o mundo se estabelece uma dialética efetiva (FANON, 2008, p. 104).

A alienação do negro "se coloca de tal forma na realidade concretamente vivida [...] que não há possibilidade de encontrar outras maneiras de ser reconhecido humano que não seja sendo branco" (FAUSTINO, 2018a, p. 55). Assim, o negro deseja ser como o branco a fim de conquistar o espaço que este tem e, para isso, nega, onde for possível, aquilo que é em direção a esse Ser deificado. Como afirma: "Alguns negros querem, custe o que custar, demonstrar aos brancos a riqueza do seu pensamento, a potência respeitável do seu espírito" (FANON, 2008, p. 27).

Esse processo caracteriza o que Neusa Souza (1983) chama de Ideal de Ego branco, um modelo em que o indivíduo busca ser perfeito, ou quase, recuperando o seu narcisismo original. "Realizar o Ideal de Ego é uma exigência - dificilmente burlável que o Superego vai impor ao Ego. E a medida de tranquilidade e harmonia interna do 
indivíduo é dada pelo nível de aproximação entre o Ego atual e o Ideal de Ego" (SOUZA, 1983, p.33).

Para o negro, no entanto, o Ideal de Ego é branco. Para alcançá-lo - ou se aproximar dele o máximo possível - é preciso rejeitar a si próprio. Como se não bastasse, se quisermos retomar o já mencionado silêncio do movimento de luta antimanicomial brasileiro diante dos efeitos do racismo, pode-se imaginar o que significou, para a maioria da população deste País, ter vivido o trauma coletivo representado pelos trezentos anos de escravidão e a consequente negação quase absoluta de sua humanidade nesse período, mas, sobretudo, a posterior recusa das elites em reconhecer e reparar material e simbolicamente esse trauma.

Se o sujeito se constitui nas relações sociais e necessita do outro para construir uma imagem de si, mas este outro não o valida, então o racismo não se resume à inferiorização do negro, mas à impossibilidade de seu reconhecimento como humano e significa que seu sofrimento sequer precisa ser reconhecido como tal. Resta ao negro, se quiser, inclusive, ter o seu sofrimento reconhecido como legítimo, aproximar-se do branco. Entretanto, por mais que tente se aproximar deste padrão de humanidade esbarra sempre na percepção fantasmagórica que fazem de si a partir da sua aparição:

Mamãe, olhe o preto, estou com medo!” Medo! Medo! E começavam a me temer. Quis gargalhar até sufocar, mas isso tornou-se impossível. Eu não aguentava mais, já sabia que existiam lendas, histórias, a história e, sobretudo, a historicidade que Jaspers havia me ensinado. Então o esquema corporal, atacado em vários pontos, desmoronou, cedendo lugar a um esquema epidérmico racial. No movimento, não se tratava mais de um conhecimento de meu corpo na terceira pessoa, mas em tripla pessoa. No trem, ao invés de um, deixavam-me dois, três lugares. Eu já não me divertia mais. Não descobria as coordenadas febris do mundo. Eu existia em triplo: ocupava determinado lugar. Ia ao encontro do outro... e o outro, evanescente, hostil mas não opaco, transparente, ausente, desaparecia. A náusea... (FANON, 2008, p.105).

\section{O RACISMO E A SAÚDE MENTAL}

De acordo com a Organização Panamericana da Saúde e a Organização Mundial da Saúde (OPS/OMS, 2016) a Saúde mental pode ser determinada por fatores diversos. Condições socioeconômicas, biológicas e psicológicas, como fatores genéticos, estressantes situações de trabalho, exclusão social, discriminação de gênero, risco de 
violência e violações dos direitos humanos, colocam em risco a Saúde mental. Para que se promova a Saúde mental, é necessário proteger, antes de mais nada, os direitos básicos civis, socioeconômicos, políticos e culturais das pessoas. Mas como garantir esses direitos em uma sociedade racialmente estruturada, como a nossa, em que a negação verbal da existência ou pertinência do racismo marca inclusive a produção teórica, o ensino e a intervenção em Saúde mental? (DAVID, 2018; LOPES, 2004).

As ações públicas de saúde mental são orientadas pela Política Nacional de Saúde Mental, criada a partir da Lei 10. 216, de 6 de abril de 2001, no âmbito do Sistema Único de Saúde (SUS). A Política tem como objetivo atender à demanda de cuidado em Saúde mental e promover a atenção integral ao usuário com transtorno mental grave. A sua efetivação dá-se pela Rede de Atenção Psicossocial (Raps), que compreende todos os recursos afetivos (relações pessoais, familiares, amigos, etc.), sanitários (serviços de saúde), sociais (moradia, trabalho, escola, esporte, etc.), econômicos (dinheiro, previdência, etc.), culturais, religiosos e de lazer, como forma de potencializar as equipes de saúde nos esforços de cuidado e reabilitação psicossocial. A Raps é composta pelos Centros de Atenção Psicossocial (CAPS), Residências Terapêuticas, Unidade Básica de Saúde (UBS), Unidades de Saúde da Família (USF), enfermarias especializadas em pronto atendimento e instituições de defesa dos direitos dos usuários (BRASIL, 2004).

Embora o Ministério da Saúde tenha redirecionado o cuidado em saúde para as estratégias nas ações de Atenção Básica (BRASIL, 2013), o CAPS ainda é considerado como o principal serviço de cuidado e atenção à Saúde mental e tem como objetivo atender à população do território que sofre com transtornos mentais graves, por meio de programas e estratégias terapêuticas, garantindo o princípio de acesso universal e respeitando as diferenças do sujeito, com um olhar voltado para sua totalidade e complexidade (BRASIL, 2004).

Ao tomar Fanon (2008) referência, destaca-se que produzir ações em Saúde mental em um contexto desigual remete necessariamente ao engajamento implicado com os sujeitos subalternizados e, sobretudo, com a luta pela transformação das condições concretas de desigualdade de acesso à saúde e qualidade de vida. A questão que se impõe é: em que medida as formulações teóricas e políticas da Saúde mental, formuladas à luz da reforma antimanicomial, estavam ou estão atentas aos efeitos 
psicossociais do racismo? A própria ideia de saúde integral, que permeia a Política Nacional de Saúde Mental, já abriria precedentes para o devido equacionamento entre racismo e Saúde mental, em uma sociedade como a brasileira, visto que prevê em suas estratégias o cuidado em território e leva em conta as diferenças que constituem o sujeito, atendendo-o em sua totalidade.

No entanto, como afirma Emiliano David (2018), a discussão da temática étnicoracial não é costumeira, nos equipamentos de saúde mental no Brasil, reproduzindo um desconhecimento ou a secundarização do sofrimento mental promovido pelo racismo. Para o autor, é comum que

os profissionais de saúde acabem reproduzindo as relações raciais hierarquizadas construídas ao longo de centenas de anos, associando cor da pele à posição hierárquica inferior, ao baixo poder aquisitivo e distinguindo condutas de cuidado entre as populações negra e branca. (DAVID, 2018, p.67).

Tal fato expressa aquilo que Jurema Werneck (2016) denomina como racismo institucional. O silêncio, ou a invisibilidade do racismo, nas políticas de saúde mental

guarda relações com o conceito de vulnerabilidade programática, uma vez que desloca-se da dimensão individual e instaura a dimensão estrutural, correspondendo a formas organizativas, políticas, práticas e normas que resultam em tratamentos e resultados desiguais.(WERNECK, 2016, p. 541).

Como forma de fazer frente às iniquidades em saúde para essa população, foi criada, em 2010, a Política Nacional de Saúde Integral da População Negra (PNSIPN), instituída pela Portaria 992, de 13 de maio de 2009, atendendo ao Estatuto da Igualdade Racial, Lei 12.288, de 20 de julho de 2010. Reconhece o racismo institucional e as desigualdades em saúde que acometem essa população, levando em consideração as condições de vida que resultam de injustos processos sociais, culturais e econômicos manifestados na história do País, colaborando para melhores condições de saúde e promovendo a equidade em saúde da população negra (BRASIL, 2013). A PNSIPN tem como objetivo geral "promover a saúde integral da população negra, priorizando a redução das desigualdades étnico-raciais, o combate ao racismo e à discriminação nas instituições e serviços do SUS” (BRASIL, 2013, p.19). 
$\mathrm{O}$ aspecto que se quer destacar aqui, ao mobilizar esses marcos normativos, é que a saúde não pode ser pensada devidamente sem a consideração dos fatores sociais que a circundam e isso não é novidade nem nos preciosos tratados da reforma sanitária que resultaram na formulação e consolidação do SUS e nem nos tratados advindos da luta antimanicomial. O que espanta, quando contrastamos a produção teórica e política sobre saúde, no Brasil, é a pouca importância dada aos efeitos do racismo, tanto sobre os determinantes sociais de saúde quanto, de forma mais direta, sobre o sofrimento psíquico (FAUSTINO, 2017).

É fundamental trazer à tona este debate - ainda que seja no momento em que o legado da luta antimanicomial e da Reforma Sanitária está sob sistemático ataque e franco desmonte. Ainda assim, é válido retomar o provérbio akan, quando afirma que "sempre é tempo de voltar e apanhar o que ficou perdido". Frantz Fanon (2008, p. 28), uma das principais inspirações de Franco Basaglia, afirmava que "a Sociedade, ao contrário dos processos bioquímicos, não escapa à influência humana" e por isso, o "prognóstico está nas mãos daqueles que quiserem sacudir as raízes contaminadas do edifício" (FANON, ano, p. 28). Estejamos prontos, assim como Fanon, para uma defesa revolucionária do humano, onde quer que ele se encontre.

\section{REFERÊNCIAS BIBLIOGRÁFICAS}

AYRES, J. R., PAIVA, V., \& BUCHALlA, C. M. Direitos Humanos e Vulnerabilidade na Prevenção e Promoção da Saúde: Uma introdução. In: V. Paiva, J. R. Ayres, \& C. M. Buchalla (Orgs.), Coletânea: Vulnerabilidade e Direitos Humanos. Prevenção e promoção da saúde: Vol. 1. Da doença à cidadania. Curitiba, PR: Juruá, 2012.

BRASIL. Ministério da Saúde. Secretaria de Atenção à saúde. Departamento de Ações Programáticas Estratégicas. Saúde mental no SUS: os centros de atenção psicossocial. Brasília: Ministério da Saúde, 2004.

BRASIL. Ministério da Saúde. Secretaria de Atenção à Saúde. Departamento de Atenção Básica. Saúde mental. Ministério da Saúde, Secretaria de Atenção à Saúde, Departamento de Atenção Básica, Departamento de Ações Programáticas Estratégicas. - Brasília: Ministério da Saúde, 2013.

BRASIL. Ministério da Saúde. Secretaria de Gestão Estratégica e Participativa. Departamento de Apoio à Gestão Participativa. Política Nacional de Saúde Integral da População Negra: uma política para o SUS. Brasília: Editora do Ministério da Saúde, 2013.

Revista da ABPN • v. 12, n. Ed. Especial - Caderno Temático: "III ANPSINEP Articulação Nacional de Psicólogas/os Negras/os e Pesquisadoras/es” • outubro de 2020, p. 6-26 
CRP - Conselho Regional de Psicologia de São Paulo. Psicologia e preconceito racial. Conselho Regional de Psicologia de São Paulo, São Paulo: CRP/SP, 2007.

DAVID, E. de C. Saúde mental e racismo: a atuação de um Centro de Atenção Psicossocial II infanto-juvenil. Dissertação (Mestrado em Psicologia Social), Programa de Estudos Pósgraduados em Psicologia Social, Pontifícia Universidade Católica, São Paulo, 2018.

FANON, F. Peau noire, masques blancs. Préface (1952) et Post face (1965) de Francis Jeanson. Editions du Seuil, 1952. Collections "esprit".

FANON, F. Pele negra, máscaras brancas. Tradução de Renato da Silveira. Salvador: EDUFBA, 2008.

FANON, F. Em defesa da revolução africana. Lisboa: Livraria Sá da Costa, 1980.

FAUSTINO, D. M. O encarceramento em massa e os aspectos raciais da exploração de classe no Brasil. In: Encarceramento em massa, símbolo do estado penal. PUC Viva, ano 11, n.39, set./dez. 2010, p. 14-30.

FAUSTINO, D. M. A emoção é negra e a razão é helênica? Considerações fanonianas sobre a (des)universalização. Revista Tecnologia e Sociedade (on-line), v. 1, 2013a, p. 121-136. Disponível em: https://periodicos.utfpr.edu.br/rts/article/view/2629/1738. Acessado em: 12 de maio de 2019.

FAUSTINO, D. M. Colonialismo, racismo e luta de classes: a atualidade de Frantz Fanon. In: V Simpósio Internacional Lutas Sociais na América Latina. Anais. 2013b, p. 216-232.

FAUSTINO, D. M. Por que Fanon, por que agora? Frantz Fanon e os fanonismos no Brasil. Tese (Doutorado em Sociologia), Programa de Pós-Graduação em Sociologia da Universidade Federal de São Carlos, 2015.

FAUSTINO, D. M. Frantz Fanon, a branquitude e a racialização: aportes introdutórios a uma agenda de pesquisas. In: MULLER; CARDOSO (org.). Branquitude: estudos sobre a identidade branca no Brasil. Curitiba: Apris, 2017.

FAUSTINO, D. M. Frantz Fanon: um revolucionário, particularmente negro. São Paulo: Ciclo Contínuo Editorial, 2018a.

FAUSTINO, D. M. Frantz Fanon: capitalismo, racismo e a sociogênese do colonialismo. Revista SER Social, v. 20, n.42, jan./jul. 2018a, p. 148-163. Disponível em: https://periodicos.unb.br/index.php/SER_Social/article/view/14288. Acessado em: 18 de novembro de 2019.

FAUSTINO, D. M. A psiquiatria revolucionária de Frantz Fanon. Quatro em um. São Paulo, Folha de São Paulo. 01/07/2020. Disponível em: https://quatrocincoum.folha.uol.com.br/br/resenhas/p/a-psiquiatria-de-

fanon?fbclid=IwAR1JVEShjwohUYbTTQ7T1yk31MVTzNzZ9kuY2n0dWXyPf8UdmhwFDFhiJo . Acessado em: 2 de julho de 2020.

FREUD, S. (1924). Mal estar da civilização. In: Edição standard brasileira das obras Completas de S. Freud. Rio de Janeiro: Imago, v. VII, 1972. 
GEISMAR, P. Fanon. Buenos Aires: Granica Editor, 1972.

GIBRAN, K. Khalil Gibran: obras completas. Editora Edicomunicaion, 2003.

GORDON, L. R. What Fanon said: a philosophical lntroduction to his life and thoughr. A Fordham Universiry Press Publication, 2015.

LOPES, F. Experiências desiguais ao nascer, viver, adoecer e morrer: tópicos em saúde da população negra. Brasília, 2004. Disponível em: <http://www.aids.gov.br/sites/default/files/projeto914bra3002.pdf> Acesso em: 17 de maio 2017.

KHALFA, J. Fanon, psiquiatra revolucionário [Apresentação]. Fanon, Frantz. Alienação e liberdade: escritos psiquiátricos. Tradução de Sebastião Nascimento. APRES. Renato Noguera. INTR. Jean Khalfa. São Paulo: Ubu. 2020.

MARTINS, E. ; SANTOS, A. de O. dos; COLOSSO, M. Relações étnico-raciais e psicologia: publicações em periódicos da SciELO e Lilacs. Psicol. teor. prat.[on-line]. 2013, v.15, n.3 [citado 2018-11-16], p. 118-133.

MÉSZÁROS, I. Para além do capital. São Paulo: Boitempo, 2006.

MOURA, C. O racismo como arma ideológica de dominação. Revista Princípios, São Paulo, n. 34, ago./out. 1994a, p. 28-38.

MOURA, C. Dialética radical do Brasil negro. São Paulo:Anita Garibaldi, 1994b.

OLIVEIRA, R. M. de S. Frantz Fanon, psicologia e psicanálise: epistemologias da violência. Revista da Associação Brasileira de Pesquisadores Negros (ABPN), v. 10, n. 24, 2018, p.40-66.

OTO, A. J.de. Frantz Fanon: política y poética dei sujeto poscolonial. México: El Colegio de México, Centro de Estudios de Asia y África, 2003.

PAIVA, V. S. F. Psicologia na saúde: sociopsicológica ou psicossocial? Inovações do campo no contexto da resposta brasileira à AIDS. Temas psicol. [online]. 2013, vol.21, n.3 [citado 2019-11-26], pp. 531-549. Disponível em: <http://pepsic.bvsalud.org/scielo.php?script=sci_arttext\&pid=S1413389X2013000300002\&lng =pt\&nrm=iso $>$ Acessado em: 14 de novembro de 2019.

PASSOS, R. G. Holocausto ou navio negreiro?: inquietações para a reforma psiquiátrica brasileira. Argumentum, v. 10, n. 3, 2018, p. 10-22.

ROSA, M. D. Vidas secas. Revista Textura. 2004.

ROSA, M. D. Psicanálise implicada: vicissitudes das práticas psicanalistas clínico-políticas. Revista da APPOA, 2013.

SOUZA, N. S. Tornar-se negro: As vicissitudes da identidade do negro brasileiro em ascensão social. Rio de Janeiro: Edições Graal, 1983.

Revista da ABPN • v. 12, n. Ed. Especial - Caderno Temático: "III ANPSINEP Articulação Nacional de Psicólogas/os Negras/os e Pesquisadoras/es” • outubro de 2020, p. 6-26 
VENTURINI, E. Em memória de uma mulher maya. Cadernos Brasileiros de Saúde Mental, v.4, n.10, 2012, p.43-61.

WERNECK, J. Racismo institucional e saúde da população negra. Saúde Soc; 25(3),2016, p. 535-549.

Recebido em: 18/09/2020

Aceito em: 01/10/2020 